\title{
SCHOOL CHILDREN IN \\ EMPLOYMENT: ISSUES AND \\ CONSIDERATIONS
}

\author{
Damian O’Neill \\ Labour Research and Evaluation, \\ Department of Labour
}

\begin{abstract}
This paper provides a brief overview of some of the main findings from a research review summarising the state of knowledge surrounding New Zealand school children (aged 17 years and under) in paid employment to early 2010. Well over a hundred thousand New Zealand school children participate in paid employment during the school term, making a substantial contribution to the NZ economy. The review brings together formative publications since 2000 and summary findings from analyses undertaken by the Department of Labour over 2009/2010. Key findings on (i) Employment participation, including participation rates, types of work and hours of work;(ii) Employment conditions, including health and safety experiences and prevalence of employment agreements and (iii) Impacts on Education and Employment Outcomes for New Zealand school children are presented and discussed. Gaps in data availability are also identified. A copy of the full Department of Labour report is available at:

http://www.dol.govt.nz/publications/research/schoolchildren-in-paidemployment/youthreport 01.asp.
\end{abstract}

\section{Introduction}

This paper summarises the main findings from a recent review on New Zealand schoolchildren in employment to early 2010. The review brings together published research findings and summary findings from analyses undertaken by the Department of Labour in 2009/10 on a number of existing data sets (previously unanalysed for this purpose).

\section{Key findings}

This review found that while our knowledge base surrounding New Zealand schoolchildren's extracurricular employment is substantive, there are gaps to our understandings. Key findings are presented below.

\section{Participation}

The study found that participation in part-time employment is a common activity for many New Zealand schoolchildren. Through the nationally representative Youth 2000 (2007) survey (Adolescent Health Research Group, 2008), around 40\% (39\%) of secondary school students working in regular part-time employment during the school term - that's around 110,000 schoolchildren making a significant contribution to the NZ economy.
Schoolchildren are increasingly likely to participate in regular paid part-time employment as they get older. Participation rates increase steadily from around a fifth for 11-year-olds (mainly boys) (Gasson et al., 2003) to more than half for 16 and 17 year olds, with a slightly higher proportion being female (Department of Labour, 2010). See Figure One below for secondary school children's participation in holiday, casual and regular part time paid employment by age.

Students are primarily motivated to work to earn money, typically for spending on extra items for their personal use, while a smaller proportion of older students are saving for study-related reasons. While relatively few students are working to earn money for their families, students from higher deprivation areas and Pacific students are more likely than other groups to indicate that this is a motivation (Department of Labour, 2010).

Students are participating in a range of roles, which vary substantially between males and females and change as schoolchildren get older. Younger students are most likely to be doing babysitting and cleaning (mainly females) and outdoors work like gardening and newspaper deliveries (mainly males). As secondary schoolchildren get older, they become increasingly likely to work in retail and hospitality. 
Most secondary school students in regular part-time employment work a moderate number of hours each week. Two-thirds work less than 10 hours a week, while around $15 \%$, mainly older students, work more than 15 hours a week. Most younger students (aged 14 and under) work less than 5 hours a week. Students typically work on 1-3 days per week, with more than half of those in work working Saturdays. Younger students are more likely to work during the week after school while older students are more likely to work evenings and weekends. Of concern, $6 \%$ of students are working more than 20 hours a week in their regular part-time jobs - a figure generally considered excessive and, based on international literature, likely to impact negatively on subsequent educational outcomes (Department of Labour, 2010).

\section{Employment conditions}

Secondary school students in employment have low levels of awareness surrounding their employment rights (Gasson et al., 2003; Pugh, 2007), low rates of union membership (Caritas, 2003) and a 50\% likelihood of having a formal written employment agreement (Pugh, 2007). Older students, typically working in larger organisations, are more likely to have formal written agreements, while younger employees, who are more likely working for family or friends of the family, are less likely to.

Lack of awareness of rights coupled with low union membership present heightened risks for schoolchildren who, by virtue of their youth and lack of experience in the workplace, may be more vulnerable to economic exploitation and injury than older workers. Many schoolchildren employees report trusting their employers to the extent that they will do work that they consider unsafe, while a small proportion will do an unsafe task because they are afraid they will lose their job if they do not (Pugh, 2007). Under the Health and Safety in Employment Act (1992) employees have the right to refuse work they consider unsafe.

Injuries are a common and occasionally serious occurrence in school children's workplaces, with onesixth of secondary school students in part-time work reportedly being injured at work in the past year. While half of these injuries appear to be relatively minor, around a fifth were severe enough to warrant a visit to a medical professional or hospital (Department of Labour, 2010). Some industries are more prone to injury and harm than others. For example, construction, agriculture and hospitality appear to be particularly risky industries for school children (Pugh, 2007).

While relatively few of the injured children blamed their employers for workplace accidents, it appears that employers are not effective in raising schoolchildren's awareness of hazards, nor their rights, in the workplace as expected under the Health and Safety in Employment Act (1992). Pugh (2007) found that a third of secondary school students indicated that their employers had not provided them with any information about workplace hazards. Inadequacies in training and supervision in their workplaces were also frequently reported.
With regards to pay, schoolchildren on the whole appear to be well or at least fairly paid. Pugh (2007) found that three-quarters of Taranaki secondary school children in work were being paid the youth minimum wage rate (for 16 and 17 year olds - set at $80 \%$ of the adult wage) or higher (at the time, $\$ 9.00$ per hour). While half were receiving between the youth rate and the adult minimum wage hourly rate, a quarter were being paid at or above the adult minimum wage per hour.

Schoolchildren are increasingly likely to receive the minimum wage set for 16 and 17-year-olds as they get older, with just under half of 13 year olds, over half of 14 year olds and two thirds of 15 -year-olds receiving the minimum youth rate (Pugh, 2007). Reflecting age-related rates of pay and hours worked, 13 to 14-year-olds are most likely to take home between $\$ 20-50$ per week, while 15 to 17 -year-olds are more likely to take home $\$ 50-100$, with over a third of 16-year-olds and over $40 \%$ of 17-year-olds taking home more than $\$ 100$ per week.

While most school children appear to be paid fairly for their services, nearly $10 \%$ of 16 -year-olds and $5 \%$ of 17 year-olds in the Pugh (2007) study reported earning less than the youth minimum wage, which was then, and remains now, illegal in the context of a formal employment relationship. Further, there is some indicative data suggesting that a small proportion (at around five to ten percent) of intermediate and secondary school students are not receiving any pay for their work or are being paid a rate at or less than a third of the youth minimum wage. While not illegal for under 16 year olds, or for 16 and 17 year olds working on the family farm or in a family business, this rate appears very low. Due to methodological limitations surrounding the research studies however, we are unable to determine the extent to which self reported rates of pay are inappropriately low or indeed unfair. For example, the survey studies documenting low rates of pay for some schoolchildren (e.g. Gasson et al, 2003; Caritas, 2003) did not specify 'work' was necessarily paid work and/or did not exclude voluntary work or chores around the home or family business. Further confusion for children in the calculation and reporting of hourly rates may contribute to overreporting of low pay rates. This area has been identified as a priority for more robust research moving forward.

\section{Impacts of extracurricular activity on education and later life employment outcomes}

Echoing the international literature, New Zealand studies indicate that, when limited to a moderate number of hours, part-time employment during the school term does not appear to have a negative impact on scholastic achievements or subsequent employment outcomes. Some NZ studies have found (albeit slight) positive associations with later life employment (Maloney, 2004). A more recent study, linking nationally representative survey data with NCEA outcomes for Year 10 and 11students (Meyer et al., 2009), found that students engaging in regular part-time work of up to 15 hours a week in 2008 achieved more NCEA credits than students who did not participate in any part-time employment. As can be seen in Figure Two below, a curvilinear relationship between hours in work and NCEA credits 
can be seen. The collective data from 2007 and 2008 suggests that optimal levels for Year 10 and 11 students sit at less than ten hours per week (and possibly as high as 6-10 hours per week), but any level of work appears to be better than none, up to the detected threshold of 15 hours per week.
Similarly, some participation in sport is associated with higher NCEA level achievement than none at all or too much. This suggests that caregivers may have a critical role to play in supporting and monitoring schoolchildren's total extracurricular activities, including employment.

Figure 1: Secondary School Children Participation in Paid Work in 2007, by Age

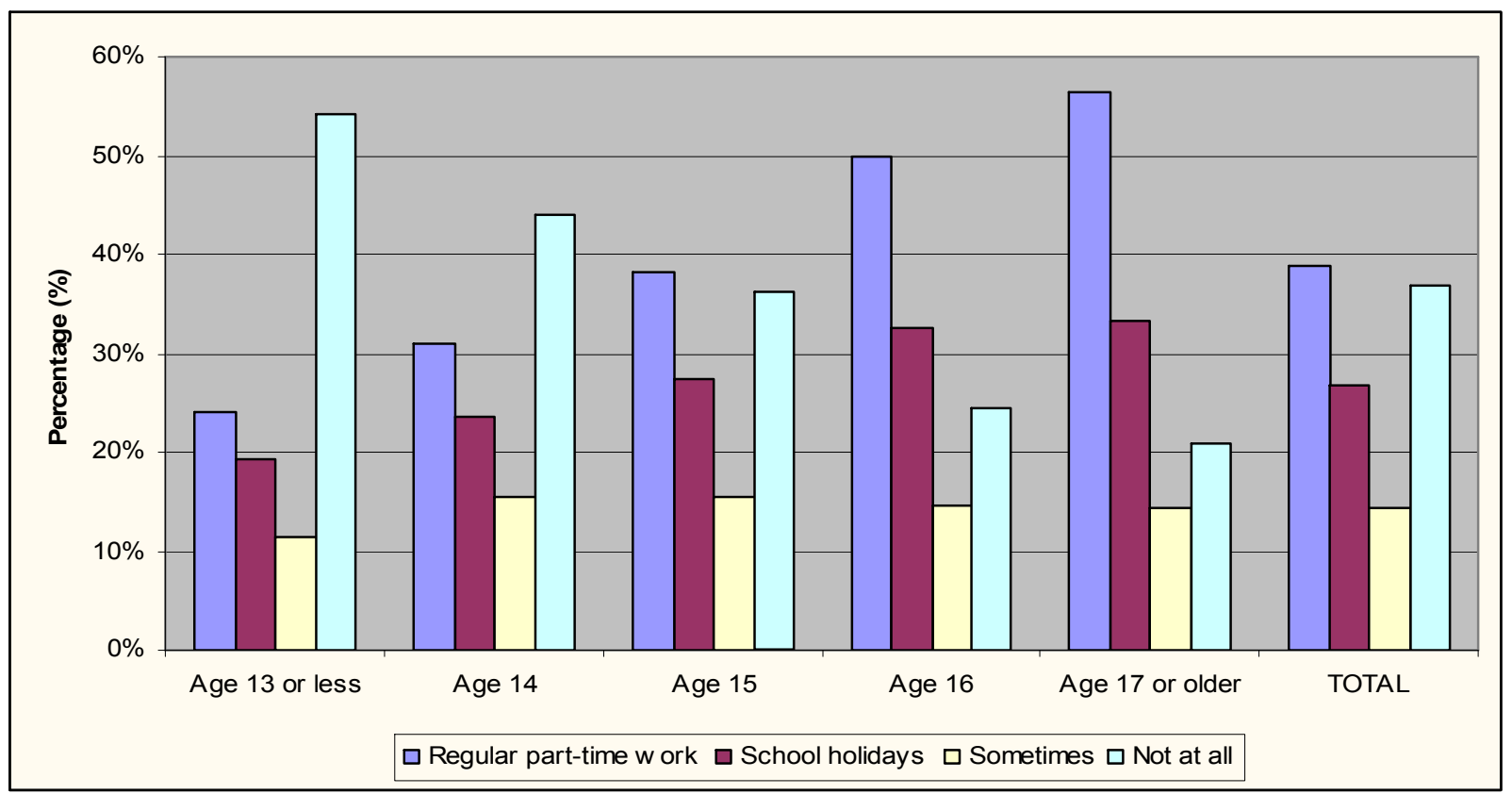

Source: DoL analysis of Youth 2000 (2007) survey data (see Adolescent Health Research Group, 2008).

Figure Two: Time spent in part-time work: Year 10 and 11 students in 2007 and 2008 and total NCEA credits attained

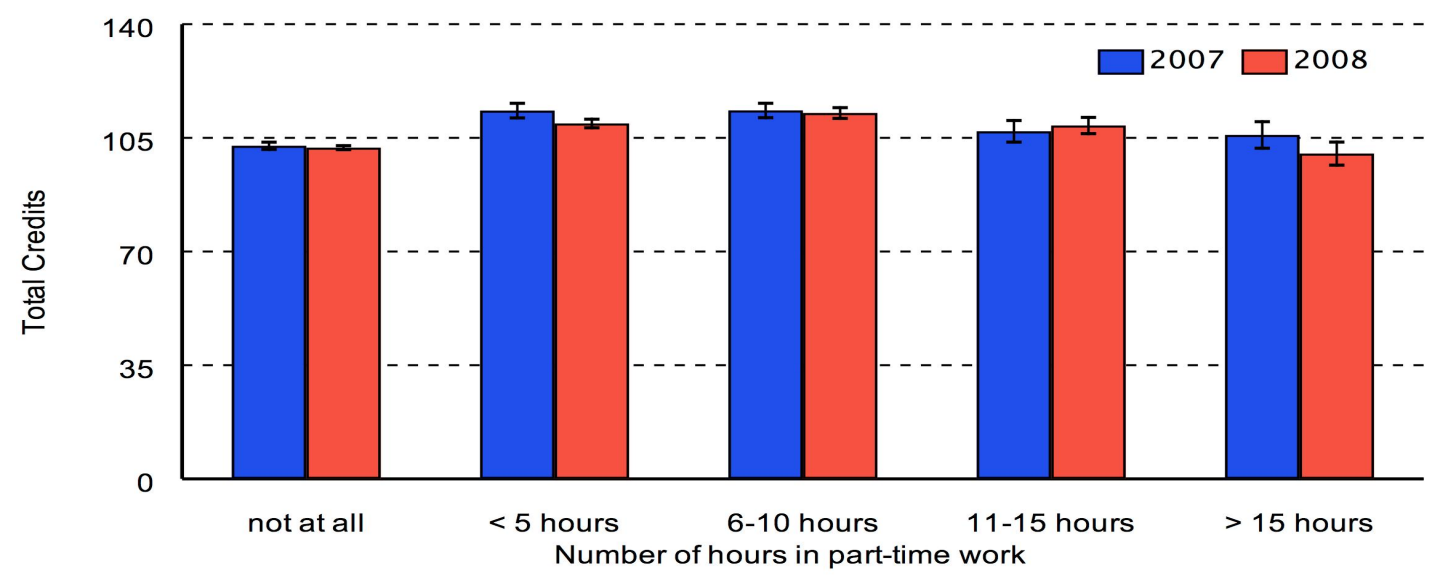

Source: Meyer et al. (2009). 


\section{Conclusions}

This review found that while we currently know a lot about NZ schoolchildren's participation in extracurricular paid employment in New Zealand, their employment conditions and associated educational and later life employment outcomes there are also many gaps to our knowledge base. Identified priorities for further research include:

- Robust knowledge of participation rates and employment conditions for schoolchildren in intermediate and primary schools

- The extent to which students working long hours spend time in study and other extracurricular activities, relative to other students, and the impacts of excessive hours on grades

- The extent to which and reasons why many employers appear to be remiss in providing school children employees with health and safety information as required under the Health and Safety in Employment Act (1992).

The review also found that while most secondary school children appear to enjoy the opportunity to work and to earn money outside of school, and that the vast majority of students appear to be fairly or well paid, some indications relating to injury rates, absence of employment agreements, low awareness of employment rights and working long or excessive hours are a cause for concern.

Several areas of Departmental activity address issues raised in the research, including the Department's harm reduction initiatives (one of which includes a focus on employment agreements), the creation and promotion of the My First Job website (a one stop shop toolkit on employment rights for youth) and support for the new longitudinal study, Growing Up In New Zealand, which is being led by the Ministry of Social Development and Auckland University.

It is anticipated that the Growing up in New Zealand study will help to fill several of our knowledge gaps. The study aims to track into adulthood 7,800 children born in the greater Auckland and Waikato regions in 2009.

Building on indications that a small proportion of 7-yearolds are engaging in part-time work, the Department has signalled a keen interest in exploring transitions into the labour market from this early age. Ideally, the research would cover work experiences and employment conditions for primary and intermediate school students (including types of jobs, hours in work, earnings, health and safety experiences) and track educational and longer term employment outcomes.

\section{References}

Adolescent Health Research Group. (2008). Youth'07: The Health and Wellbeing of Secondary School Students in New Zealand: Technical Report. University of Auckland, Auckland.

Caritas. (2003). Protecting Children at Work: Children's Work Survey 2003. Caritas Aotearoa New Zealand, Wellington.

Department of Labour (2010). School Children in Paid Employment: A Summary of Research Findings. Department of Labour, Wellington.

Gasson, N.R., Linsell, C., Gasson, J. and MundyMcPherson, S. (2003). Young People and Work. University of Otago College of Education, Dunedin.

Maloney, T. (2004). The Effects of In-school and Intertiary Employment on Academic Achievement and Labour Market Transitions: Evidence from the Christchurch Health and Development Study. New Zealand Department of Labour, Wellington..

Meyer, L., McClure, J., Weir, K., Walkey, F. and McKenzie, L. (2009). Motivation and Achievement at Secondary School: The relationship between NCEA design and student motivation and achievement: A three year followup Summary report. Jessie Hetherington Centre for Educational Research and the School of Psychology, Victoria University of Wellington, Wellington.

Pugh, J. (2007). Health and Safety Knowledge of Young Workers: A Study of School-aged, Part-time Workers in the Taranaki Region. Department of Labour, Wellington. 
